ing would, moreover, account for the slight decrease of muscular volume observed in s'rong tetanic contraction. For, according to the experiments of Quincke, the abiorption of water by organised bodies generally leads to a slight condensation. ${ }^{1}$ By this condensation further heat is developed, and this heat might, by raising the temperature of the doubly-refractive elements, be partially transformed into mechanical energy, and in this way contribute to the production of muscular force.

Yet I cannot consider this explanation as sufficient for all the facts. The same argument which in our eyes seems to dispose of the hypothesis of the identity of chemical attraction and muscular force, viz. the infinitesimally small quantity of substance which is chemically active during a simple contraction, seems to me to present a fundamental difficulty here also. It is hard to understand how through a change in the material composition, effected at one infinitesmal point within a soft watery substance, the whole mass should shorten and thicken unless there proceeds from the centre of chemical activity a considerable amount of kinetic energy throughout the substance.

The microscopic appearances which prove the turgescence of the doubly-refractive elements during a contraction, do not exclude a direct thermo-dynamical effect. For the almost complete identity in the changes of form, and of the optical and mechanical properties which the doubly refractive constituents of all histological elements undergo during chemical and thermal contraction, seems to bear out the hypothesis, that in the thermal shortening of doubly-refractive elements, through the absorption of watery fluid, we get a shifting of solid and liquid substances analogous to that of turgescence. With most of the microscopical appearances, especially the so-called fixed contraction waves, we have, moreover, to do with a high degree of tetanic contraction, or even with rigor, in which, on account of the greatly increased chemical action, a chemically-caused turgescence may have combined in a considerable degree with the thermal contraction.

Hence, we may conclude that chemical contraction by turgescence of the inotagmata is most likely a constant concomitant of the thermal contraction of living muscle, but that compared with the latter, in a single contraction at least of striated fibres, the former is of little or no consequence as regards the shortening effect.

Chemiotonus and Thermotonus. - Both processes will probably also take part in varying proportion in the tomus of muscle, which in some cases will approach more to pure chemiotonus, in others more to pure thermotonuts.

Catuses of the Relaxation of Muscle. Theoretical Considerations. Conclusion. - With regard to the relaxation of muscle, according to our theory this must be caused either by cooling, or by the withdrawal of water from the doubly-refractive particles. Indeed, we have found that generally doublyrefractive histological elements, even if they be lifeless like our violin strings, lengthen again upon cooling after they have been contracted by heat, and that they lengthen upon neutralisation or diffusion, after they have been contracted by absorption at an ordinary temperature.

In a normal relaxation the muscle seems to return com. pletely to its initial state. Of course its store of energy has diminished in proportion to the quantity of mechanical work and heat which have proceeded from it, but, on account of the relatively infinitesimal quantity of substance which is thereby consumed, this return will necessarily seem to be complete even in the case of the isolated muscle.

When analysing the phenomena of relaxation more exactly, we shall light on several possibilities, the discussion of which would be very interesting with regard to the theory of muscle-life. I shall restrict myself to the phenomena of the relaxation following on thermal contraction.

Here, in the first place, we might conceive that the doublyrefractive inotagmata are destroyed in the thermal shortening, so that each of them perform; its function once only. The lengthening of the muscular fibrils would then probably be caused solely by the elastic powers of the parts passively extended or compressed by the shortening of the inotagmata. Upon a fresh stimulation other inotagmata would, in consequence of the combustion of other thermogenic molecules, be active, perish, \&c. Through the activity of the formative matter

1 In the thermal contraction of tendons and strings I have not yet been able to convince myself of a decrease in volume.

No. I 326 , vor. $5 \mathrm{I}]$ of the living muscle-fibre, the place of the lost inotagmata would be continually or periodically filled by others, probably through the same process of organic crystallisation by which during ontogenesis the doubly-refracting particles in the muscle are produced and disposed.

Against this hypothesis, however, or at least against its general validity, various objections may be put forward. I will mention two only of the most important of them.

There seems to be no doubt but that the doubly-refractive particles of the muscle consist of an albuminous substance, and that they together make up a sensible part of the whole albumin of the muscle.fibrils. In that case it would be most improbable that a great increase of muscular work should not at all, or very slightly only, increase the elimination of nitrogen. To account for this, we should have to recur to an auxiliary hypothesis, and assume either that the nitrogenous remainder of the destroyed inotagma is retained within the body-perhaps in the muscle-for purposes of anabolism, or, which is most improb. able indeed, that other organs saved just as much albumin as was decomposed above the normal quantity during the con. traction of the muscles.

A second objection consists in the fact that after heating tetanising muscles until they are rigid, the doubly-refractive power of the sarcous elements will be found still very great.

The other possibility is that the inotagmata may be preserved, and consequently on cooling may return to their former state, and therefore will do work by shortening as often as we choose. In this case muscle would not only seem to offer, but would offer in fact, a most striking resemblance to a thermodynamic machine, the solid particles of the framework of which are not destroyed through the chemical process producing the actual energy. No more than such a machine would the muscle require a perpetual renewal of the framework for the continuation of its activity; it would only want a periodic supply of fresh heating material.

This representation, as you see, will sufficiently account for the fact, which would otherwise remain surprising, that muscular work has such a small influence on the elimination of nitrogen. The facts of microscopic observation also agree with it.

But a further discussion of the two possibilities would lead us too far. The purpose of this lecture was not to record a complete inquiry into all the phenomena of muscular activity. I have wished chiefly to draw attention to a series of facts which I hold to be of great importance for a deeper insight into the essence of muscular contractility, in so far as they prove the existence of certain material dispositions and processes (admitting of closer experimental examination), by means of which mechanical work may be generated in the muscle by chemical energy.

\section{THE SNAIL FAUNA OF THE GREATER ANTILLES.}

THE West Indian Arcbipelago has long been known to present some interesting problems in the distribution of its land fauna. These peculiarities, it will be remembered, led Wallace to infer the previous existence of a land connection of the greater islands with one another and with the mainland; while others have claimed that the islands have always been distinct, and have been colonised by the agency of currents, winds, and other indirect means of dispersal. An interesting contribution on this subject has recently appeared in the form of a study of the distribution of the West Indian land and fresh-water molluscs, by Mr. C. T. Simpson, of the U.S. National Museum, from whose paper we extract the following conclusions. A considerable portion of the land snail fauna of the Greater Antilles seems to be ancient and indigenous. There appears to be good evidence of a general elevation of the Greater Antillıan region, probably some time during the Eocene, after most of the important groups of snails had come into existence. At this time the larger islands were united, and were connected with Central America by way of Jamaica and possibly across the Yucatan Channel. There was then a considerable exchange of species between the two regions. At some time during this elevation there was probably a landway from Cuba across the Bahama plateau to the Floridean area, over which certain groups of Antillean land molluscs crossed. The more northern isles of the Lesser Antilles, if then elevated, have probably been since submerged. After the period of 
elevation there followed one of general subsidence, and first Jamaica, then Cuba, and afterwards Haiti and Puerto Rico were separated. The connection between the Antilles and the mainland was broken, and the Bahama region, if it had been previously elevated above the sea, was submerged, the subsidence continuing until only the summits of the mountains of the four Greater Antillean islands remained above the water. Then followed another period of elevation, which has lasted no doubt until the present time, and the large areas of limestone uncovered (of Miocene, Pliocene, and post-Pliocene age) in the Greater Antilles have furnished an admirable field for the development of the groups of land snails that survived on the summits of the islands. The Bahamas and the Lesser Antilles were subsequently raised above the surface, and have been colonised by forms chiefly drifted in the former case from Cuba and Haiti, and in the latter case from South America, while a few stragglers have been carried by sea no doubt from the Greater Antilles, and have settled on the more northern of the Windward Islands.

\section{UNIVERSITY AND EDUCATIONAL INTELLIGENCE.}

A Deputation from the Association of Head Masters of Higher-Grade and Organised Science Schools was received on Thursday last, by Mr. Acland, at the offices of the Science and Art Department; Major.General Sir John Donnelly being present at the interview. The deputation was the outcome of a very large and representative meeting of the association, held at Derby, to consider the new rules for organised science schools lately issued by the Department. The importance of the new regulations lies in the fact that under them a system of secondary schools will be inaugurated and carried on under the control of, and supported to a great extent by, the Science and Art Department. The organised science schools at present in existence include nearly all the more important higher-grade schools, the day schools of technical institutions, and a considerable number of grammar schools. The principal changes proposed in the new rules are the partial substitution of inspection for examination, the introduction of special courses of instruction for women students, the inclusion of a fair proportion of lit erary work in the curriculum, and the addition to it of practical work in physics and biology. A long dis. cussion, lasting over two hours, took place, at the end of which Mr. Acland stated that he hoped to be able to meet the wishes of the deputation with regard to many of the points raised, and promised, at the end of a week or ten days, to make a definite statement of the alterations the Department would be prepared to make.

Geometrical Drawing has hitherto been included in Science Subject I. (Practical, Plane, and Solid Geometry) of the Science and Art Department. It has just keen decided, however, to make Geometrical Drawing a separate subject under the Art portion of the Department's Directory; so the syllabus of the Elementary Stage of Science Subject I, will in future include only plane geometry, solid geometry, and graphic arithmetic. The changes will come into force for the session $1895-96$.

THE Senate of Glasgow University have resolved to confer the degree of Doctor of Laws on the following:-Sir John Neilson Cuthbertson; Mr. James G. Fraser, Fellow of Trinity College, Cambridge; Mr. W. E. H. Lecky; Mr. David Robertson, Millport; Dr. T. E. Thorpe, F.R.S. ; SurgeonMajor Lawrence A. Waddell, I.M.S., Bengal.

THE ninth Session of the Edinburgh Summer Meeting is arranged to take place in August. Prof. Geddes and Mr. William Sharp lecture in the section of Philosophy, Social Science, and Anthropology; and the prospectus also includes the names of M. Demolins, editor of the Science Sociale, of Dr. Wenley, Dr. Delius, and others. Under Civics and Hygiene are the names of Dr. Dyer, M. Paul Desjardins, M. Elisée Reclus, Dr. Irvine, Miss Jane Hay, and Dr. Stephens. Mr. Goodchild and Mr. Herbertson undertake the department of Geography in its widest sense; while Mr. J. Arthur Thomson and Mr. Turnbull have charge of the Biology. There will be many other fealures of interest, including a series of educational conferences.

No. I 326 , vOL. 517
THE Professorship of Natural History at the Royal Agricultural College, Cirencester, rendered vacant in December last by the death of Prof. Harker, has now been filled by the appointment of Mr. Theodore T. Groom, late Scholar of St. John's College, Cambridge, and Lecturer and Demonstrator at the Yorkshire College, Leeds. Mr. Groom at one time occupied the Cambridge table at the Zoological Station, Naples, where he successfully carried out some valuable researches, the results of which were communicated to the Royal Society of London, and published in their Philosothical Transactions. The chair of Natural History at the College has been filled by a succession of very able men, among whom, in addition to Prof. Harker, may be mentioned such names as Buckman, $\mathrm{McNab}$, and ThiseltonDyer.

\section{SCIENTIFIC SERIALS.}

American Fournal of Science, March.-The Appalachian type of folding in the White Mountain Range of Inyo County, California, by C. D. Walcott. In the broad palæozoic area between the Sierra Nevada on the west and the early palæozoic shore-line on the east (Colorado) a period of folding and thrust-faulting was followed by a period of vertical faulting, which displaced the strata that had been folried and faulted in the preceding epoch. The extent and character of this disturbance can only be determined by a careful study of each of these mountain ranges for a distance of over five hundred miles east and west, and probably one thousand miles north and south. - The succession of fossil faunas at Springfield, Missouri, by Stuart Weller. The rocks studied are beds of grey limestone with lenticular chert concretions, and form part of the Mississippian series. The faunas of the lower part of the section may be correlated with the Burlington faunas of Iowa, and those of the upper part with the Keokuk faunas. The whole series of faunas is continuous, and the whole series of rocks should be designated by a single name. The term Osage, suggested in 1891 by $\mathrm{H}$. S. Williams, is recommended.Drift boulders between the Mohawk and Susquehanna rivers, by A. P. Brigham. The Archæan and the more northern Palæozoic fragments are strewn over the whole district at all altitudes, but diminishing southward in size, and sparse in amount on the highest hills, especially to the southward, where the tops of the ranges are often surprisingly free from transported material. Actual reduction of the general surface towards base level doubtless proceeded rapidly during glacial time, but even then the process was rapid only in the geological sense, and the result a minute fraction of what has been accom. plished since the region became a land surface.

Bulletin of the American Mathematical Society, vol. i. 5 . (New York, February 1895.) - On a certain class of canonical forms, by Mr. R. A. Roberts, is a paper, read before the Society at its December meeting, which treais of an interesting class of theorems occurring in the consideration of algebraical quantics. - "Hayward's Vector Algebra" is a review, by Prof. M. Böcher, of the algebra of coplanar vectors and trigonometry, which deals out praise and its opposite in about equal proportions. - Apolar triangles on a conic is a very interesting paper by Prof. F. Morley. - The remaining short notices comprise an instance where a well-known test to prove the simplicity of a simple group is insufficient, by G. H. Miller, and an account of the Lobachevsky Memorial Volume, 1793-1893. Amongst the notes is a bare statement of Prof. Cayley s death. -The usual new publications list concludes the number.

Symons's Monthly Meteorological Magazine for March contains another striking proof of the severity of the frost in February last, as shown by the temperature of the earth at Camden Square, in the north-west of London. The thermometer with its bulb one foot below the surface was first read on January 1, 1871 . Prior to 1895 , it was never below $32^{\circ}$, and only reached that point in 1880 . But in February last there were twelve consecutive days on which the thermometer was below $32^{\circ}$. In country districts, the frost penetrated to a much greater depth, and this subject will probably be referred to in a future number of the magazine. A careful observer at Berkhamsted states that the frost there penetrated to a depth of I foot 8 inches.

Internationales Archiv für Ethnrglathie, Band. vii. Heft v. and vi. 1894.-Prof. H. H. Giglioli, in his "Notes on some 